Published in final edited form as:

Clin Cancer Res. 2019 March 15; 25(6): 1980-1988. doi:10.1158/1078-0432.CCR-18-2965.

\title{
Calcium Intake and Survival after Colorectal Cancer Diagnosis
}

\author{
Wanshui Yang ${ }^{\# 1}$, Yanan Ma ${ }^{\# 1,2}$, Stephanie Smith-Warner 3,4 , Mingyang Song ${ }^{3,4,5,6}$, Kana \\ Wu $^{3}$, Molin Wang ${ }^{7}$, Andrew T. Chan ${ }^{1,5,8,9}$, Shuji Ogino ${ }^{4,10,11}$, Charles S. Fuchs ${ }^{12,13,14}$, Vitaliy \\ Poylin ${ }^{15}$, Kimmie Ng $^{16}$, Jeffrey A. Meyerhardt ${ }^{16}$, Edward L. Giovannucci ${ }^{1,3,4}$, Xuehong \\ Zhang ${ }^{1}$ \\ ${ }^{1}$ Channing Division of Network Medicine, Department of Medicine, Brigham and Women's \\ Hospital and Harvard Medical School, Boston, Massachusetts. \\ ${ }^{2}$ Department of Biostatistics and Epidemiology, School of Public Health, China Medical University, \\ Shenyang, Liaoning, P.R. China. \\ ${ }^{3}$ Department of Nutrition, Harvard T.H. Chan School of Public Health, Boston, Massachusetts. \\ ${ }^{4}$ Department of Epidemiology, Harvard T.H. Chan School of Public Health, Boston, \\ Massachusetts. \\ ${ }^{5}$ Clinical and Translational Epidemiology Unit, Massachusetts General Hospital and Harvard \\ Medical School, Boston, Massachusetts. \\ ${ }^{6}$ Division of Gastroenterology, Massachusetts General Hospital, Boston, Massachusetts. \\ ${ }^{7}$ Department of Biostatistics, Harvard T.H. Chan School of Public Health, Boston, Massachusetts. \\ ${ }^{8}$ Broad Institute of Massachusetts Institute of Technology and Harvard, Cambridge, \\ Massachusetts. \\ ${ }^{9}$ Department of Immunology and Infectious Diseases, Harvard T.H. Chan School of Public Health, \\ Boston, Massachusetts.
}

\footnotetext{
Corresponding Author: Xuehong Zhang, Brigham and Women's Hospital and Harvard Medical School, 181 Longwood Avenue, Room 453, Boston, MA 02115. Phone: 617-525-0342; Fax: 617-525-2008; poxue@channing.harvard.edu.

Authors' Contributions

Conception and design: W. Yang, C.S. Fuchs, E.L. Giovannucci, X. Zhang Development of methodology: W. Yang, M. Song, C.S. Fuchs, K. Ng, X. Zhang Acquisition of data (provided animals, acquired and managed patients, provided facilities, etc.): A.T. Chan, C.S. Fuchs, E.L. Giovannucci, X. Zhang Analysis and interpretation of data (e.g., statistical analysis, biostatistics, computational analysis): W. Yang, Y. Ma, S. Smith-Warner, M. Song, K. Wu, M. Wang, A.T. Chan, S. Ogino, C.S. Fuchs, K. Ng, J.A. Meyerhardt, X. Zhang

Writing, review, and/or revision of the manuscript: W. Yang, Y. Ma, S. Smith-Warner, M. Song, K. Wu, A.T. Chan, S. Ogino, V. Poylin, K. Ng, J.A. Meyerhardt, E.L. Giovannucci, X. Zhang

Administrative, technical, or material support (i.e., reporting or organizing data, constructing databases): A.T. Chan, X. Zhang Study supervision: A.T. Chan, C.S. Fuchs, X. Zhang

Disclosure of Potential Conflicts of Interest

C.S. Fuchs is a consultant/advisory board member for Entrinsic Health, Taiho, Genentech, CytomX, Eli Lilly, Sanofi, Unum

Therapeutics, and Merck. K. Ng reports receiving commercial research grants from Pharmavite, LLC. No potential conflicts of interest were disclosed by the other authors.

Disclaimer

The funders had no role in design of the study; the collection, analysis, or interpretation of the data; the writing of the article; or the decision to submit the article for publication.

Note: Supplementary data for this article are available at Clinical Cancer Research Online (http://clincancerres.aacrjournals.org/).

The costs of publication of this article were defrayed in part by the payment of page charges. This article must therefore be hereby marked advertisement in accordance with 18 U.S.C. Section 1734 solely to indicate this fact.
} 
10Department of Oncologic Pathology, Dana-Farber Cancer Institute and Harvard Medical School, Boston, Massachusetts.

${ }^{11}$ Program in MPE Molecular Pathological Epidemiology, Department of Pathology, Brigham and Women's Hospital and Harvard Medical School, Boston, Massachusetts.

${ }^{12}$ Department of Medical Oncology, Yale Cancer Center, New Haven, Connecticut.

${ }^{13}$ Department of Medicine, Yale School of Medicine, New Haven, Connecticut.

${ }^{14}$ Department of Medical Oncology, Smilow Cancer Hospital, New Haven, Connecticut.

${ }^{15}$ Department of Surgery, Division of Colon and Rectal Surgery, Beth Israel Deaconess Medical Center in Boston, Massachusetts.

${ }^{16}$ Department of Medical Oncology, Dana-Farber Cancer Institute and Harvard Medical School, Boston, Massachusetts.

\# These authors contributed equally to this work.

\section{Abstract}

Purpose-Although evidence suggests an inverse association between calcium intake and colorectal cancer incidence, the influence of calcium on survival after colorectal cancer diagnosis remains unclear.

Experimental Design-We prospectively assessed the association of postdiagnostic calcium intake with colorectal cancer-specific and overall mortality among 1,660 nonmetastatic colorectal cancer patients within the Nurses' Health Study and the Health Professionals Follow-up Study. Patients completed a validated food frequency questionnaire between 6 months and 4 years after diagnosis and were followed up for death. Multivariable hazard ratios (HRs) and 95\% confidence intervals $(95 \% \mathrm{CI})$ were calculated using Cox proportional hazards regression.

Results-Comparing the highest with the lowest quartile intake of postdiagnostic total calcium, the multivariable HRs were $0.56\left(95 \% \mathrm{CI}, 0.32-0.96 ; P_{\text {trend }}=0.04\right)$ for colorectal cancer-specific mortality and $0.80\left(95 \% \mathrm{CI}, 0.59-1.09 ; P_{\text {trend }}=0.11\right)$ for all-cause mortality. Postdiagnostic supplemental calcium intake was also inversely associated with colorectal cancer-specific mortality (HR, $\left.0.67 ; 95 \% \mathrm{CI}, 0.42-1.06 ; P_{\text {trend }}=0.047\right)$ and all-cause mortality $(\mathrm{HR}, 0.71 ; 95 \%$ CI, $0.54-0.94 ; P_{\text {trend }}=0.008$ ), although these inverse associations were primarily observed in women. In addition, calcium from diet or dairy sources was associated with lower risk in men.

Conclusions-Higher calcium intake after the diagnosis may be associated with a lower risk of death among patients with colorectal cancer. If confirmed, these findings may provide support for the nutritional recommendations of maintaining sufficient calcium intake among colorectal cancer survivors.

\section{Introduction}

Colorectal cancer remains the third most common type of cancer diagnosed in both sexes in the United States, and the number of colorectal cancer survivors continues to grow in the United States $(1,2)$. As of January 2016, over 1.5 million Americans were colorectal cancer survivors (3). To deliver quality cancer care, the Institute of Medicine highlighted the 
importance of healthful lifestyle changes including weight management, physical activity, and a healthy diet for cancer survivors (4). However, research that defines the benefits of lifestyle changes among cancer survivors is limited, particularly for diet recommendations (5). Hence, there is an urgent need to investigate dietary factors in relation to survivorship among patients with established colorectal cancer.

Currently, about $43 \%$ of the U.S. population (including almost $70 \%$ of older women) is using supplemental calcium (6). Calcium may biologically influence colorectal carcinogenesis by reducing proliferation of colonic epithelial cells (7), inducing apoptosis (8), and inhibiting colonic KRAS mutations (9). In fact, the most comprehensive review by the World Cancer Research Fund and American Institute for Cancer Research concluded that supplemental calcium intake probably protects against colorectal cancer development (10). Moreover, three (11-13) controlled clinical trials have reported an inverse association between calcium and/or other supplements and the risk of colorectal adenoma recurrence, whereas others $(14,15)$ found no association, although there were variations in their intervention treatments among these studies (11-15). Despite considerable research on calcium intake and colorectal cancer risk, the influence of calcium intake on colorectal cancer survival is much less studied. Few existing studies (16-20) reported null associations between prediagnostic calcium intake and colorectal cancer survival. To our knowledge, only the Cancer Prevention Study II (CPS-II) cohort has examined postdiagnostic calcium intake and reported a statistically significant $28 \%$ reduced risk for all-cause mortality and a marginally statistically significant $41 \%$ reduced risk for colorectal cancer-specific mortality comparing extreme quartile intake groups (20). Clearly, more studies are warranted to confirm and better characterize these potentially important associations. Furthermore, we are not aware of any previous studies assessing the association between changes in calcium intake after colorectal cancer diagnosis (e.g., difference between prediagnostic and postdiagnostic intake) and cancer survival. This issue is important, because cancer survivors and clinicians want to know whether lifestyle changes (e.g., increasing intake of calcium) after the diagnosis may provide benefits.

Therefore, we conducted this study to investigate postdiagnostic calcium intake in relation to survival among patients with colorectal cancer by utilizing data from the Nurses' Health Study (NHS) and the Health Professionals Follow-up Study (HPFS). Compared with previous studies including CPS-II (16-20), our cohorts have longer follow-up periods, larger number of colorectal cancer patients, and detailed information on prediagnostic and postdiagnostic calcium intake as well as clinicopathologic factors.

\section{Materials and Methods}

\section{Study cohort}

Participants in this study were selected from among 173,229 men and women in NHS (121,700 women) and HPFS (51,529 men). For NHS, the recruitment for U.S. female registered nurses ages 30 to 55 years was completed in 1976. For HPFS, the recruitment for U.S. male professionals ages 40 to 75 years was completed in 1986. In each cohort, questionnaires were administrated biennially to collect and update information on 
demographic characteristics, lifestyle factors, and medical history, with follow-up rates over $90 \%$.

The incident colorectal cancer cases were defined as a primary tumor with International Classification of Diseases-9 codes of 153 and 154. Participants from the two cohorts were asked for written permission to obtain medical records and pathologic reports if they reported colorectal cancer on biennial questionnaires. For nonresponders, we searched the state cancer registries and the National Death Index to identify deaths and to ascertain any colorectal cancer diagnosis that contributed to death or was a secondary diagnosis (21). For all deaths attributable to colorectal cancer, we requested permission to review medical records from next-of-kin. All possible colorectal cancer cases were further confirmed through review of medical and pathologic records. A study physician who was blinded to exposure data abstracted information on tumor anatomic location, stage, and histology type.

By the end of June 1, 2012, for the NHS, and January 31, 2012, for the HPFS, 3,924 cases of colorectal cancer were identified. After exclusion (see the flow chart in Supplementary Fig. S1), a total of 1,660 participants ( $n=1,022$ in the NHS and 638 in the HPFS) who were diagnosed with colorectal cancer and completed the food frequency questionnaire (FFQ) after diagnosis were included in this study. The study protocol was approved by the Institutional Review Boards of the Brigham and Women's Hospital and Harvard T.H. Chan School of Public Health.

\section{Study outcomes}

Deaths and causes of death among 1,660 included colorectal cancer patients were identified through review of the National Death Index, and family members or the postal system in response to the follow-up questionnaires. Over $98 \%$ of deaths have been identified using these methods (21).

\section{Assessments of calcium intake}

Assessment of calcium intake and other dietary factors was described in detail elsewhere (22-24). Briefly, in each cohort, self-reported dietary information was collected at baseline and updated almost every 4 years using a validated (25-27) semiquantitative 131-item (or more) FFQ. In addition, we collected information on calcium supplements and multivitamin use in each biennial questionnaire. We used the composition database from the U.S. Department of Agriculture to calculate nutrient intake by multiplying the frequency of each food consumed by the nutrient content per serving of that food, and summing across all foods and beverages $(22,23)$. Consistent with previous studies from the same cohorts $(22$, 23), we calculated individual's total calcium intake by summing calcium from dietary sources including fortified foods plus supplements. The calcium from dairy sources alone was calculated by summing the contributions of all dairy products and food items containing dairy products. Calcium from nondairy sources was calculated by subtracting dairy calcium intake from total dietary calcium intake $(22,23)$. Supplemental calcium intake in this study included calcium from both calcium supplement use and multivitamin use $(22,23)$.

The FFQs used in this study have been validated among 173 women from the NHS (27) and among 127 men from the HPFS (25). The energy-adjusted correlation coefficients of total 
calcium intake comparing the FFQ and the average of multiple 1-week diet records (four for women and two for men) were 0.63 for women (27) and 0.61 for men (25). The correlation coefficients for dietary calcium intake were 0.70 for women (27) and 0.60 for men (25).

To avoid potential impact of active treatment and consistent with our previous study from the same cohorts (28), postdiagnostic intake in the current analysis was defined as dietary intake reported on the first FFQ collected at least 6 months but no more than 4 years after diagnosis (median, 2.1 years). Prediagnostic intake assessment was based on the last FFQ reported before colorectal cancer diagnosis (median, 1.9 years).

\section{Assessment of covariates}

We inquired on covariates including adult body weight, physical activity (METS-hours/ week), cigarette smoking, and aspirin use every 2 years. Other dietary factors including intakes of alcohol, vitamin $\mathrm{D}$, folate, red meat and processed meat, and fat were collected and updated almost every 4 years using validated FFQs in each cohort $(25,26)$.

\section{Statistical analysis}

Person-years of follow-up were calculated from the return date of the FFQ that was used for postdiagnostic assessment to death, or the end of the study period (June 1, 2012, for the NHS, January 31, 2012, for the HPFS), whichever came first. In the colorectal cancerspecific mortality analysis, death from colorectal cancer was the primary end point, and deaths from other causes were censored. In the all-cause mortality analysis, death from any cause was the end point.

Cox hazard regression models were used to calculate HRs and 95\% confidence intervals (CI) of death, with time since diagnosis as the time scale, accounting for left truncation due to differences between patients in the timing of postdiagnostic assessment (29). Both stage IIII colorectal cancer patients and colorectal cancer patients with unknown stage were included in the analysis. We tested proportional hazards assumption by including the interaction term between total calcium and calcium by food source and follow-up time into the model, and found no evidence for violation of this assumption (all $P>0.05$ ). We adjusted for tumor differentiation, anatomic subsites, year of diagnosis, prediagnostic calcium intake, postdiagnostic body mass index (BMI), physical activity, smoking, multivitamin use, and other supplement use (defined by the sum of vitamin A, C, E, selenium, and zinc), and intake of alcohol, vitamin D, folate, total fat, and total calorie. We simultaneously stratified age, tumor stage, and study cohort (sex) in the Cox regression model. We categorized energy adjusted calcium intake into quartile categories based on the distribution of each cohort. Given no evidence of significant between-study heterogeneity for total and supplemental calcium ( $P$ values for heterogeneity by gender $>0.05)$, we combined results from the two cohorts to maximize the statistical power. However, we did not pool results for postdiagnostic dietary or dairy calcium because there was significant heterogeneity between the two cohorts. The trend tests were conducted using the median of each category of calcium intake as a continuous variable, and $P$ value for trend was calculated using a Wald test (30). Consistent with our previous studies $(22,23)$, we also presented the HRs of mortality per $300 \mathrm{mg}$ daily increment of calcium intake. In addition, 
we evaluated the influence of calcium on survival by different food sources (i.e., dietary calcium, dairy calcium, and supplemental calcium intake). Furthermore, we evaluated changes in calcium intake after colorectal cancer diagnosis (i.e., difference between prediagnostic and postdiagnostic intake) and cancer survival. Subgroup analyses were conducted by lifestyle and clinicopathologic factors. Test of interaction was conducted using the likelihood ratio test by comparing the model with product terms between stratified covariate and calcium intake with the models without these terms. Consistent with previous studies from our cohorts (31-33), we excluded participants with missing values on exposure data at baseline.

We conducted several sensitivity analyses. First, considering the possible selection bias by exclusion of patients from study due to lack of postdiagnostic dietary data, we also applied inverse probability weighting (IPW) method (34). In this method, complete cases (i.e., individuals without missing data) are weighted by the inverse of their probability of being a complete case. The weight was inverse of the probability of calcium data availability estimated based on a model for calcium data availability status (34). Second, prediagnostic versus postdiagnostic calcium intake were dichotomized into low (the first and second quartile categories) versus high (the third and fourth quartile categories), resulting in four mutually exclusive categories based on pre- and postdiagnostic intakes [low (prediagnostic)low (postdiagnostic), low-high, high-low, and high-high]. These four groups were evaluated in relation to survival. Third, we also repeated analysis by excluding unspecified tumor stage patients. In addition, we repeated analysis that included stage IV colorectal cancer patients. Fourth, we further adjusted for the 2010 alternative healthy eating index (AHEI-2010) score in replacement of dietary covariates in the models, including postdiagnostic alcohol consumption and postdiagnostic intake of total fat, folate, and vitamin D, multivitamin use, and other supplement use. Last, we evaluated the association between calcium supplement use (i.e., supplemental calcium intake from calcium supplement use only but not from multivitamin use) and mortality among colorectal cancer survivors. We used SAS 9.4 for all analyses (SAS Institute).

\section{Results}

During a median follow-up of 9.4 years, we documented a total of 1,660 patients with colorectal cancer, of which 646 deaths were identified, including 210 colorectal cancerspecific deaths. Participants with higher total calcium intake were slightly older, more physically active, less likely to smoke and drink alcohol, and more likely to use aspirin and consume vitamin D, total folate, and total fat (Table 1).

Postdiagnostic total calcium intake was inversely associated with colorectal cancer-specific mortality and all-cause mortality. Results were similar in three models (Table 2). Comparing the highest with the lowest quartile intake of postdiagnostic total calcium, the multivariable HRs were 0.56 (95\% CI, 0.32-0.96; $P_{\text {trend }}=0.04$ ) for colorectal cancer-specific mortality and $0.80\left(95 \% \mathrm{CI}, 0.59-1.09 ; P_{\text {trend }}=0.11\right)$ for all-cause mortality. These inverse associations remained when we used the IPW method (Supplementary Table S1). 
Postdiagnostic supplemental calcium intake was inversely associated with colorectal cancerspecific mortality (HR comparing the highest with the lowest quartile intake, $0.67 ; 95 \% \mathrm{CI}$, $\left.0.42-1.06 ; P_{\text {trend }}=0.047\right)$ and all-cause mortality $\left(\mathrm{HR}, 0.71 ; 95 \% \mathrm{CI}, 0.54-0.94 ; P_{\text {trend }}=\right.$ 0.008 , Table 2). To tease out the possible association of supplemental calcium intake from multivitamin sources, we assessed the association on calcium supplement use only and found similar results (Supplementary Table S2). In subgroup analysis, we investigated whether the association between total calcium intake and mortality differed by other possible predictors of cancer survival, including age, smoking, alcohol consumption, BMI, physical activity, aspirin use, vitamin D, cancer locations, and stage, and found no statistically significant interactions (Table 3).

Compared with patients who did not appreciably alter their supplemental calcium intake (amount of change $<150 \mathrm{mg} / \mathrm{day}$ ), those who increased intake by at least $300 \mathrm{mg} / \mathrm{day}$ had an HR of 0.64 (95\% CI, 0.40-1.00) for colorectal cancer-specific mortality. However, those who decreased their intake at least $300 \mathrm{mg} /$ day had an HR of $1.23\left(95 \% \mathrm{CI}, 0.72-2.11 ; P_{\text {trend }}\right.$ $=0.01$; Table 4 ). In addition, compared with low-low intake groups (low intake level before cancer diagnosis and low after cancer diagnosis), the inverse associations generally appeared stronger in low-high groups (Supplementary Table S3). After we excluded colorectal cancer patients with unspecified tumor stage $(n=208)$ or included stage IV patients $(n=91)$, the results did not materially change (Supplementary Table S4). Likewise, when we adjusted for the AHEI-2010 dietary pattern score in replacement of all dietary covariates in the models, the results were very similar to those in the main analysis (data not shown).

When stratified by sex, we observed significant inverse association between supplemental calcium intake and mortality among women but not with dietary or dairy calcium intake (Supplementary Table S5). In men, intake of total calcium, dietary calcium, and dairy calcium was associated with lower risk of mortality, but supplemental calcium intake was not associated with risk of mortality (Supplementary Table S6). There was no association between prediagnostic calcium intake and mortality among colorectal cancer patients in our cohorts (Supplementary Table S7).

\section{Discussion}

In this large cohort of patients with nonmetastatic colorectal cancer, we found that higher postdiagnostic calcium intake, especially supplemental calcium intake, was independently associated with lower risk of colorectal cancer-specific and all-cause mortality. These observations, along with our previous findings of inverse associations between calcium intake and colorectal cancer risk $(22,35)$, provide additional support for the role of calcium intake in both colorectal cancer development and prognosis.

Consistent with an inverse association between calcium intake and colorectal cancer incidence $(22,35-37)$, the current study suggested that patients who had higher calcium intake after diagnosis had substantially lower risk of mortality. Only one published study to date has assessed the risk of all-cause and colorectal cancer-specific mortality associated with postdiagnostic calcium intake. This study, conduct among 1,111 colorectal cancer patients from the CPS-II cohort, reported an inverse association for both all-cause mortality 
and colorectal cancer-specific mortality (20), which were generally consistent with our findings. Similar to previous studies (16-20), we found no association between prediagnostic calcium intake and mortality among colorectal cancer patients.

Some potential mechanisms might explain the observed beneficial associations. In vitro studies showed that calcium could promote E-cadherin expression, suppress beta-catenin/Tcell factor activation $(38,39)$, and activate $\mathrm{p} 38$ mitogen-activated protein kinase cascade through activation of calcium-sensing receptor (CASR; refs. 40, 41), thereby regulating the balance between proliferation, differentiation, and apoptosis of colonic epithelial cells, and inhibit malignant progression. Besides CASR-mediated effects, other potential mechanisms include reduced solubility of damaging bile acids (42), fatty acids (36), and heme (43) in the colonic lumen and direct effects on reducing proliferation of colonic epithelial cells (7). We are not aware of any randomized clinical trials that were specifically designed to test the effect of calcium intake on colorectal cancer survival, although several clinical trials were conducted among patients with colorectal adenoma, and inconsistently showed that daily treatment with calcium and/or other supplements was associated with lower risk of colorectal adenoma recurrence (11-15). However, we do not have data on colorectal cancer recurrence for this study.

We observed significant inverse associations with higher supplemental calcium intake for both all-cause mortality and colorectal cancer-specific mortality, especially in women. The ingestion of calcium supplements, but not for calcium-rich foods, may lead to an acute increase in serum calcium $(44,45)$. This increase could be sustained in the long term leading to a persistent decrease in serum parathyroid hormone (PTH; refs. 46, 47). The reduced PTH concentrations could be associated with colonic neoplasm occurrence and progression (48, 49). Thus, higher supplemental calcium intake might have a more pronounced effect on cancer survival. Alternatively, calcium supplement users may have had more healthy behaviors or use of other supplements, which may in turn have a lower risk of mortality. However, the inverse associations persisted in this study after we adjusted for multivitamin use and other supplement use as well as a wide range of potential prognostic factors. In our cohorts, supplemental calcium intake contributed to 25\% (1990s) to 35\% (2000s) of total calcium intake in women but only contributed to $3 \%$ (1990s) to $8 \%$ (2000s) in men (22). Thus, the much lower intake average and less frequent use might partially explain the null associations with supplemental calcium intake among men. Our results might have an important implication for clinical practice if validated in future studies. In men, however, we observed significant inverse associations with total, dietary, and dairy calcium intake. This was unexpected, and the possible difference might be due to chance. Clearly, we should interpret these results cautiously because of the very limited number of patients in men. Overall, differential association between calcium and mortality by gender or by food sources warrants further investigation.

Strengths of our study include prospective cohort design, large sample size, relatively long follow-up, detailed collection of prediagnostic and postdiagnostic data, and validated colorectal cancer outcomes including diagnosis and death. In addition, the availability of the prediagnostic data allowed us to evaluate the associations between changes in intake after diagnosis and mortality. 
There are several limitations. First, assessment of calcium intake using FFQs was subject to measurement errors, but the FFQs used in our cohorts have been comprehensively validated (25-27). Second, as an observational study, residual confounding cannot be totally ruled out, although our detailed data resources enabled us to adjust for a wide range of potential confounders.

Third, due to the limited number of colorectal cancer patients with tumor molecular biomarker data, we did not consider or adjust for tumor molecular markers such as microsatellite instable status in the current analysis. Other limitations of this study include the lack of detailed data on cancer treatment and recurrence, as well as information on adherence to treatment, and treatment adverse effects. However, over $65 \%$ of patients had stage I or stage II disease in the analysis, in which surgery alone would generally be the standard of care. In addition, adjuvant therapy was largely standardized and correlated with disease stage. Thus, adjusting for tumor stage may reduce such potential confounding bias by treatment. Furthermore, in a subset of patients who provided chemotherapy data (43\%), there was no difference in total calcium intake between those who received chemotherapy and those who did not.

In summary, we observed that higher postdiagnostic calcium intake, including from supplement use, might be associated with lower risk of death among colorectal cancer patients. Our findings need to be confirmed by further studies, including possible clinical trials of calcium supplementation in patients with nonmetastatic colorectal cancer.

\section{Supplementary Material}

Refer to Web version on PubMed Central for supplementary material.

\section{Acknowledgments}

We would like to thank the participants and staff of the NHS and the HPFS for their valuable contributions as well as the following state cancer registries for their help: AL, AZ, AR, CA, CO, CT, DE, FL, GA, ID, IL, IN, IA, KY, LA, ME, MD, MA, MI, NE, NH, NJ, NY, NC, ND, OH, OK, OR, PA, RI, SC, TN, TX, VA, WA, and WY. The authors assume full responsibility for analyses and interpretation of these data.

This work was supported by grants from the NCI at the NIH (grant numbers R01 CA137178 to A.T. Chan, K24 DK098311 to A.T. Chan, R35 CA197735 to S. Ogino, U01 CA167552 to W.C. Willett, and K07 CA188126 to X. Zhang). A.T. Chan is a Stuart and Suzanne Steele MGH Research Scholar. W. Yang was supported by scholarship grants from Chinese Scholarship Council. X. Zhang was also supported by the American Cancer Society Research Scholar Grant (grant number RSG NEC-130476) and Boston Nutrition Obesity Research Center Pilot and Feasibility Award. The HPFS and NHS were supported by the NCI at the NIH (grant numbers UM1CA186107, P50CA127003, P01CA87969, R01CA49449, and UM1CA167552).

\section{Appendix}




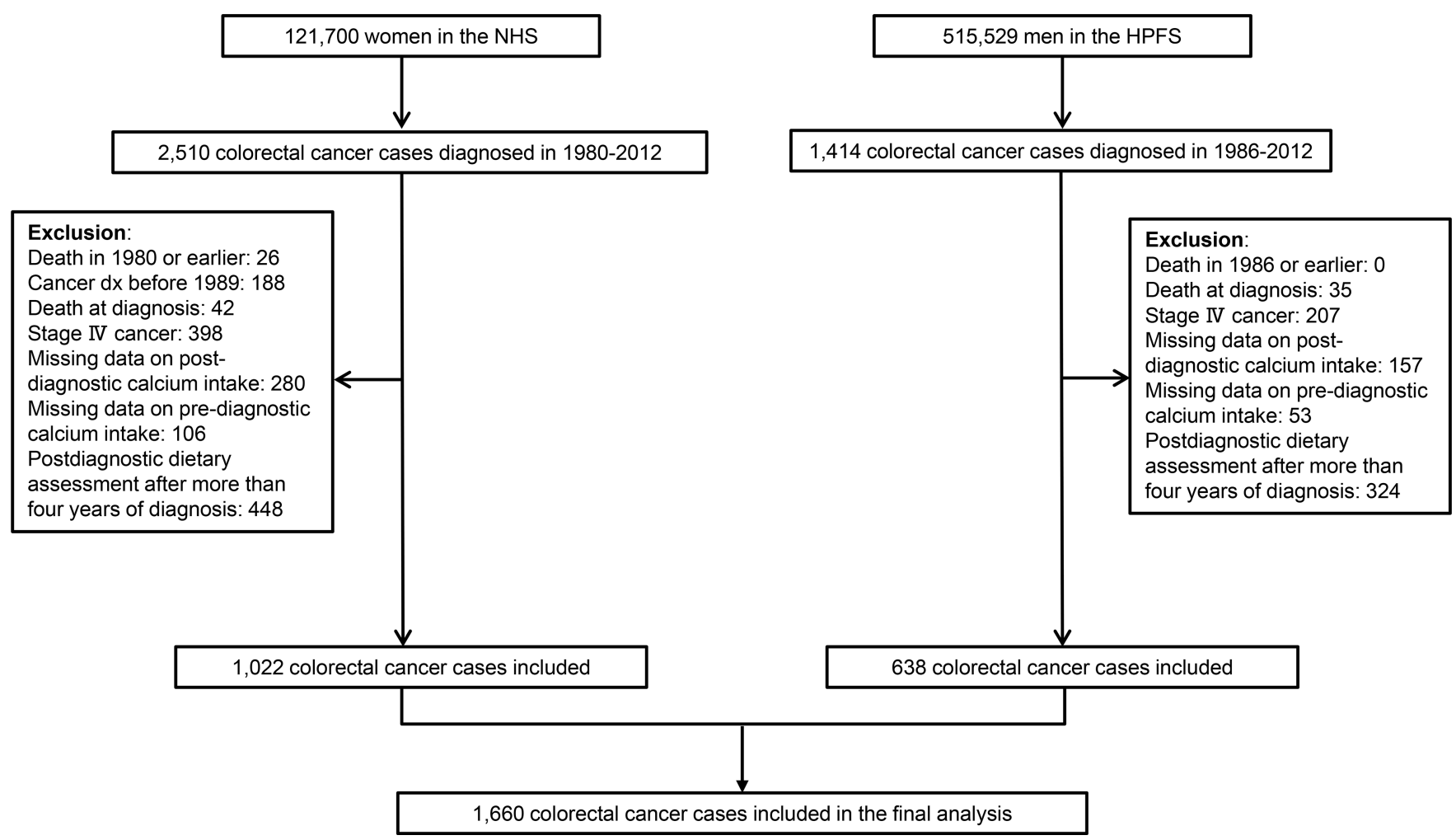

Appendix Figure A1.

Flow chart of the study population in the Nurses' Health Study (1980-2012) and Health

Professionals Follow-up Study (1986-2012)

\section{References}

1. Siegel RL, Fedewa SA, Anderson WF, Miller KD, Ma J, Rosenberg PS, et al. Colorectal cancer incidence patterns in the United States, 1974-2013. J Natl Cancer Inst 2017;109.

2. Siegel RL, Miller KD, Fedewa SA, Ahnen DJ, Meester RGS, Barzi A, et al. Colorectal cancer statistics, 2017. CA Cancer J Clin 2017;67: 177-93. [PubMed: 28248415]

3. Miller KD, Siegel RL, Lin CC, Mariotto AB, Kramer JL, Rowland JH, et al. Cancer treatment and survivorship statistics, 2016. CA Cancer J Clin 2016;66:271-89. [PubMed: 27253694]

4. Demark-Wahnefried W, Rogers LQ, Alfano CM, Thomson CA, Courneya KS, Meyerhardt JA, et al. Practical clinical interventions for diet, physical activity, and weight control in cancer survivors. CA Cancer J Clin 2015; 65:167-89. [PubMed: 25683894]

5. Jones LW, Demark-Wahnefried W. Diet, exercise, and complementary therapies after primary treatment for cancer. Lancet Oncol 2006;7: 1017-26. [PubMed: 17138223]

6. Bailey RL, Dodd KW, Goldman JA, Gahche JJ, Dwyer JT, Moshfegh AJ, et al. Estimation of total usual calcium and vitamin D intakes in the United States. J Nutr 2010;140:817-22. [PubMed: 20181782]

7. Lipkin M, Newmark H. Calcium and the prevention of colon cancer. J Cell Biochem Suppl 1995;22:65-73. [PubMed: 8538212]

8. Lamprecht SA, Lipkin M. Cellular mechanisms of calcium and vitamin D in the inhibition of colorectal carcinogenesis. Ann N Y Acad Sci 2001;952: 73-87. [PubMed: 11795445]

9. Llor X, Jacoby RF, Teng BB, Davidson NO, Sitrin MD, Brasitus TA. K-ras mutations in 1,2dimethylhydrazine-induced colonic tumors: effects of supplemental dietary calcium and vitamin D deficiency. Cancer Res 1991; 51:4305-9. [PubMed: 1868452] 
10. World Cancer Research Fund, American Institute for Cancer Research. Diet, nutrition, physical activity and colorectal cancer. 2017.

11. Baron JA, Beach M, Mandel JS, van Stolk RU, Haile RW, Sandler RS, et al. Calcium supplements for the prevention of colorectal adenomas. Calcium Polyp Prevention Study Group. N Engl J Med 1999;340:101-7. [PubMed: 9887161]

12. Grau MV, Baron JA, Sandler RS, Haile RW, Beach ML, Church TR, et al. Vitamin D, calcium supplementation, and colorectal adenomas: results of a randomized trial. J Natl Cancer Inst 2003;95:1765-71. [PubMed: 14652238]

13. Bonithon-Kopp C, Kronborg O, Giacosa A, Rath U, Faivre J. Calcium and fibre supplementation in prevention of colorectal adenoma recurrence: a randomised intervention trial. European Cancer Prevention Organisation Study Group. Lancet 2000;356:1300-6. [PubMed: 11073017]

14. Baron JA, Barry EL, Mott LA, Rees JR, Sandler RS, Snover DC, et al. A trial of calcium and vitamin D for the prevention of colorectal adenomas. N Engl J Med 2015;373:1519-30. [PubMed: 26465985]

15. Hofstad B, Almendingen K, Vatn M, Andersen SN, Owen RW, Larsen S, et al. Growth and recurrence of colorectal polyps: a double-blind 3-year intervention with calcium and antioxidants. Digestion 1998;59:148-56. [PubMed: 9586828]

16. Dray X, Boutron-Ruault MC, Bertrais S, Sapinho D, Benhamiche-Bouvier AM, Faivre J. Influence of dietary factors on colorectal cancer survival. Gut 2003;52:868-73. [PubMed: 12740344]

17. Dik VK, Murphy N, Siersema PD, Fedirko V, Jenab M, Kong SY, et al. Prediagnostic intake of dairy products and dietary calcium and colorectal cancer survival-results from the EPIC cohort study. Cancer Epidemiol Biomarkers Prev 2014;23:1813-23. [PubMed: 24917183]

18. Zell JA, McEligot AJ, Ziogas A, Holcombe RF, Anton-Culver H. Differential effects of wine consumption on colorectal cancer outcomes based on family history of the disease. Nutr Cancer 2007;59:36-45. [PubMed: 17927500]

19. Slattery ML, French TK, Egger MJ, Lyon JL. Diet and survival of patients with colon cancer in Utah: is there an association? Int J Epidemiol 1989;18:792-7. [PubMed: 2559896]

20. Yang B, McCullough ML, Gapstur SM, Jacobs EJ, Bostick RM, Fedirko V, et al. Calcium, vitamin D, dairy products, and mortality among colorectal cancer survivors: the Cancer Prevention StudyII Nutrition Cohort. J Clin Oncol 2014;32:2335-43. [PubMed: 24958826]

21. Stampfer MJ, Willett WC, Speizer FE, Dysert DC, Lipnick R, Rosner B, et al. Test of the National Death Index. Am J Epidemiol 1984;119: 837-9. [PubMed: 6720679]

22. Zhang X, Keum N, Wu K, Smith-Warner SA, Ogino S, Chan AT, et al. Calcium intake and colorectal cancer risk: results from the nurses' health study and health professionals follow-up study. Int J Cancer 2016;139: 2232-42. [PubMed: 27466215]

23. Wu K, Willett WC, Fuchs CS, Colditz GA, Giovannucci EL. Calcium intake and risk of colon cancer in women and men. J Natl Cancer Inst 2002; 94:437-46. [PubMed: 11904316]

24. Yang W, Liu L, Masugi Y, Qian ZR, Nishihara R, Keum N, et al. Calcium intake and risk of colorectal cancer according to expression status of calcium-sensing receptor (CASR). Gut 2018;67:1475-83. [PubMed: 28676564]

25. Rimm EB, Giovannucci EL, Stampfer MJ, Colditz GA, Litin LB, Willett WC. Reproducibility and validity of an expanded self-administered semiquantitative food frequency questionnaire among male health professionals. Am J Epidemiol 1992;135:1114-26; discussion 27-36. [PubMed: 1632423]

26. Feskanich D, Rimm EB, Giovannucci EL, Colditz GA, Stampfer MJ, Litin LB, et al. Reproducibility and validity of food intake measurements from a semiquantitative food frequency questionnaire. J Am Diet Assoc 1993;93: 790-6. [PubMed: 8320406]

27. Willett WC, Sampson L, Stampfer MJ, Rosner B, Bain C, Witschi J, et al. Reproducibility and validity of a semiquantitative food frequency questionnaire. Am J Epidemiol 1985;122:51-65. [PubMed: 4014201]

28. Meyerhardt JA, Giovannucci EL, Ogino S, Kirkner GJ, Chan AT, Willett W, et al. Physical activity and male colorectal cancer survival. Arch Intern Med 2009;169:2102-8. [PubMed: 20008694] 
29. Cain KC, Harlow SD, Little RJ, Nan B, Yosef M, Taffe JR, et al. Bias due to left truncation and left censoring in longitudinal studies of developmental and disease processes. Am J Epidemiol 2011;173:1078-84. [PubMed: 21422059]

30. Wu H, Flint AJ, Qi Q, van Dam RM, Sampson LA, Rimm EB, et al. Association between dietary whole grain intake and risk of mortality: two large prospective studies in US men and women. JAMA Intern Med 2015;175:373-84. [PubMed: 25559238]

31. Song M, Zhang X, Meyerhardt JA, Giovannucci EL, Ogino S, Fuchs CS, et al. Marine omega-3 polyunsaturated fatty acid intake and survival after colorectal cancer diagnosis. Gut 2017;66:17906. [PubMed: 27436272]

32. Song M, Wu K, Meyerhardt JA, Ogino S, Wang M, Fuchs CS, et al. Fiber intake and survival after colorectal cancer diagnosis. JAMA Oncol 2018; 4:71-9. [PubMed: 29098294]

33. Hu Y, Ding M, Yuan C, Wu K, Smith-Warner SA, Hu FB, et al. Association between coffee intake after diagnosis of colorectal cancer and reduced mortality. Gastroenterology 2018;154:916-26e9. [PubMed: 29158191]

34. Liu L, Nevo D, Nishihara R, Cao Y, Song M, Twombly TS, et al. Utility of inverse probability weighting in molecular pathological epidemiology. Eur J Epidemiol 2018;33:381-92. [PubMed: 29264788]

35. Keum N, Aune D, Greenwood DC, Ju W, Giovannucci EL. Calcium intake and colorectal cancer risk: dose-response meta-analysis of prospective observational studies. Int J Cancer 2014;135:1940-8. [PubMed: 24623471]

36. Newmark HL, Wargovich MJ, Bruce WR. Colon cancer and dietary fat, phosphate, and calcium: a hypothesis. J Natl Cancer Inst 1984;72:1323-5. [PubMed: 6587152]

37. Garland C, Shekelle RB, Barrett-Connor E, Criqui MH, Rossof AH, Paul O. Dietary vitamin D and calcium and risk of colorectal cancer: a 19-year prospective study in men. Lancet 1985;1:307-9. [PubMed: 2857364]

38. Chakrabarty S, Radjendirane V, Appelman H, Varani J. Extracellular calcium and calcium sensing receptor function in human colon carcinomas: promotion of E-cadherin expression and suppression of beta-catenin/TCF activation. Cancer Res 2003;63:67-71. [PubMed: 12517779]

39. Lamprecht SA, Lipkin M. Chemoprevention of colon cancer by calcium, vitamin D and folate: molecular mechanisms. Nat Rev Cancer 2003;3: 601-14. [PubMed: 12894248]

40. Ye CP, Yano S, Tfelt-Hansen J, MacLeod RJ, Ren X, Terwilliger E, et al. Regulation of a Ca2+activated $\mathrm{K}+$ channel by calcium-sensing receptor involves p38 MAP kinase. J Neurosci Res 2004;75:491-8. [PubMed: 14743432]

41. Hobson SA, Wright J, Lee F, McNeil SE, Bilderback T, Rodland KD. Activation of the MAP kinase cascade by exogenous calcium-sensing receptor. Mol Cell Endocrinol 2003;200:189-98. [PubMed: 12644311]

42. Bernstein C, Holubec H, Bhattacharyya AK,Nguyen H, Payne CM, Zaitlin B, et al. Carcinogenicity of deoxycholate, a secondary bile acid. Arch Toxicol 2011;85:863-71. [PubMed: 21267546]

43. Sesink AL, Termont DS, Kleibeuker JH, Van der Meer R. Red meat and colon cancer: the cytotoxic and hyperproliferative effects of dietary heme. Cancer Res 1999;59:5704-9. [PubMed: 10582688]

44. Reid IR, Schooler BA, Hannan SF, Ibbertson HK. The acute biochemical effects of four proprietary calcium preparations. Aust N Z J Med 1986; 16:193-7. [PubMed: 3463271]

45. Green JH, Booth C, Bunning R. Postprandial metabolic responses to milk enriched with milk calcium are different from responses to milk enriched with calcium carbonate. Asia Pac J Clin Nutr 2003;12: 109-19. [PubMed: 12737020]

46. Reid IR, Ames R, Mason B, Reid HE, Bacon CJ, Bolland MJ, et al. Randomized controlled trial of calcium supplementation in healthy, nonosteoporotic, older men. Arch Intern Med 2008;168:2276-82. [PubMed: 19001206]

47. Heaney RP. Ethnicity, bone status, and the calcium requirement. Nutr Res 2002;22:153-78.

48. Fedirko V, Riboli E, Bueno-de-Mesquita HB, Rinaldi S, Pischon T, Norat T, et al. Prediagnostic circulating parathyroid hormone concentration and colorectal cancer in the European Prospective 
Investigation into Cancer and Nutrition cohort. Cancer Epidemiol Biomarkers Prev 2011; 20:76778. [PubMed: 21378267]

49. Calvo N, Gentili C, de Boland AR. Parathyroid hormone and the regulation of cell cycle in colon adenocarcinoma cells. Biochim Biophys Acta 2011;1813:1749-57. [PubMed: 21703311] 


\section{Translational Relevance}

Calcium may decrease the risk of developing colorectal cancer. However, the influence of calcium consumption on survival after colorectal cancer diagnosis remains unclear. We prospectively assessed the association of postdiagnostic calcium intake with colorectal cancer-specific and overall mortality among 1,660 colorectal cancer patients within the Nurses' Health Study and the Health Professionals Follow-up Study. We found that postdiagnostic calcium intake, especially from supplements, may reduce risk of death among colorectal cancer patients. These results were consistent with the only prospective study examining the association between calcium intake and mortality after colorectal cancer diagnosis in the Cancer Prevention Study II cohort. If validated in future studies, our findings support nutritional recommendations of maintaining sufficient calcium intake among colorectal cancer survivors. 


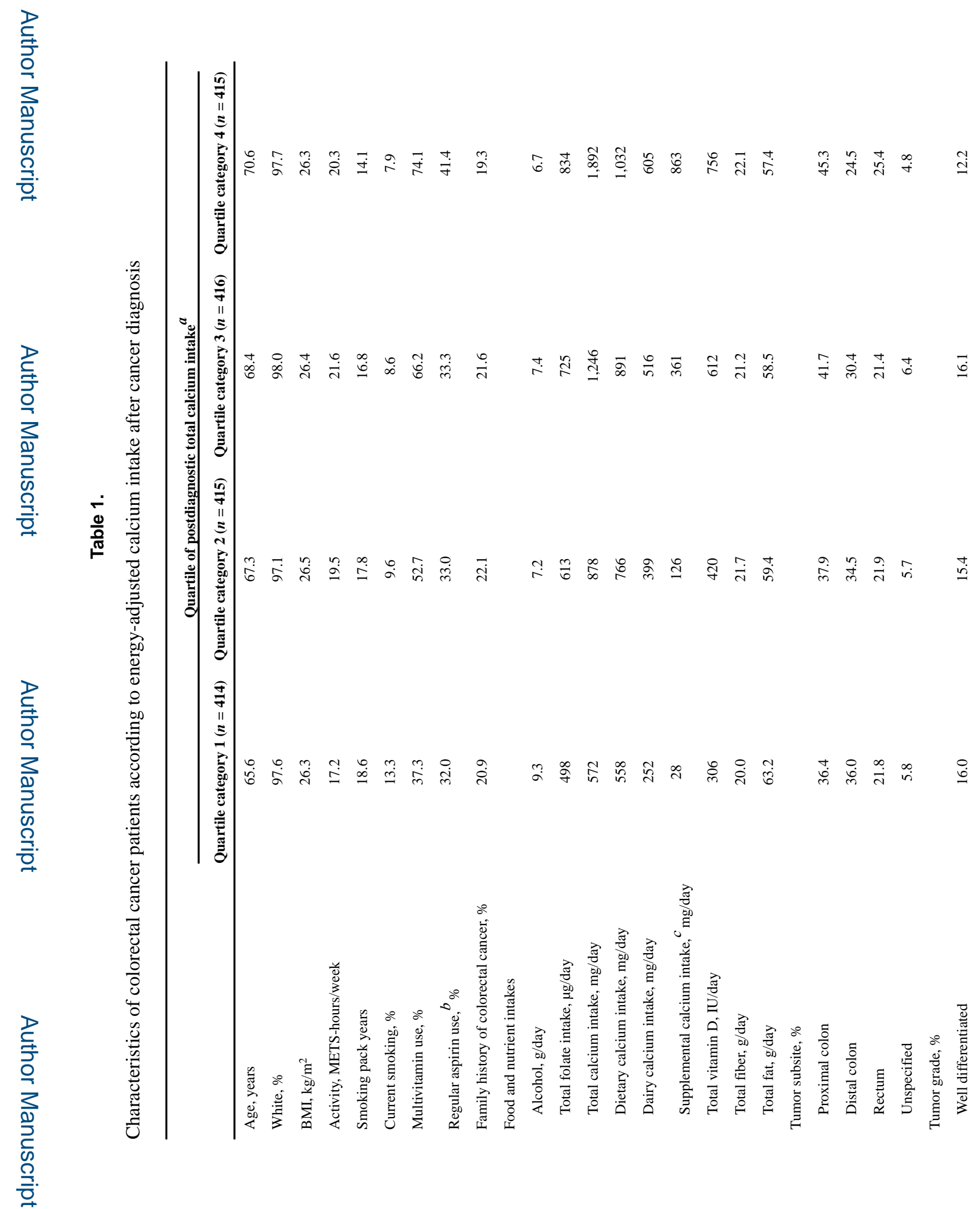

Clin Cancer Res. Author manuscript; available in PMC 2020 February 15. 


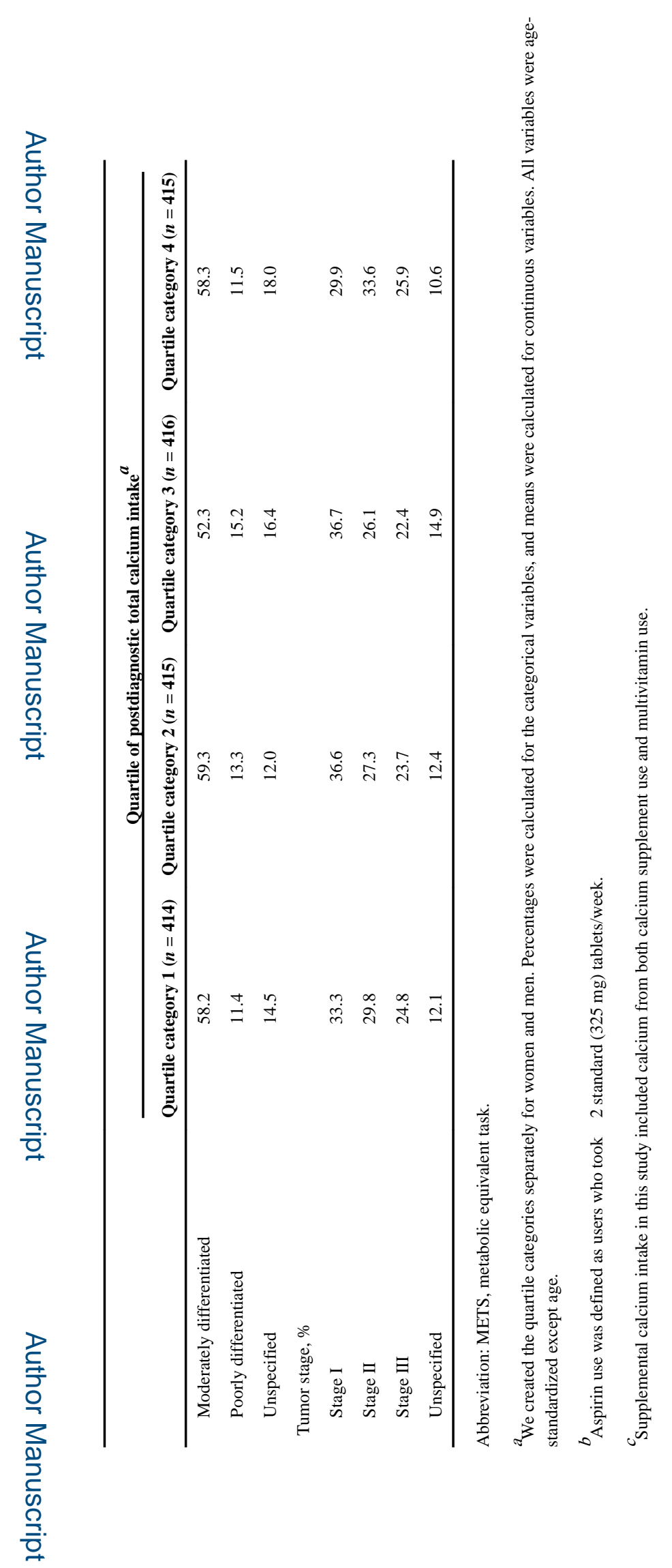

Clin Cancer Res. Author manuscript; available in PMC 2020 February 15. 


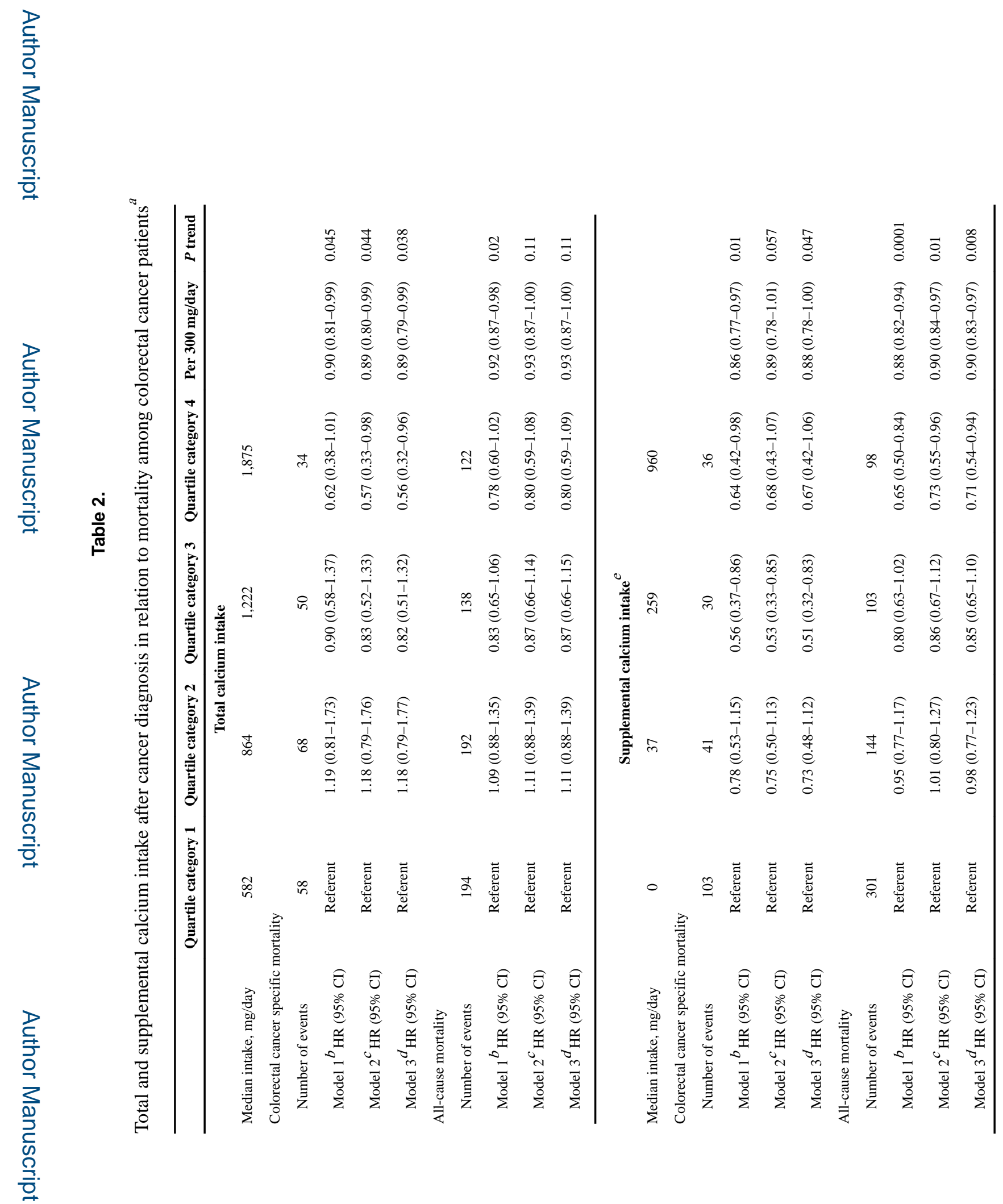

Clin Cancer Res. Author manuscript; available in PMC 2020 February 15. 


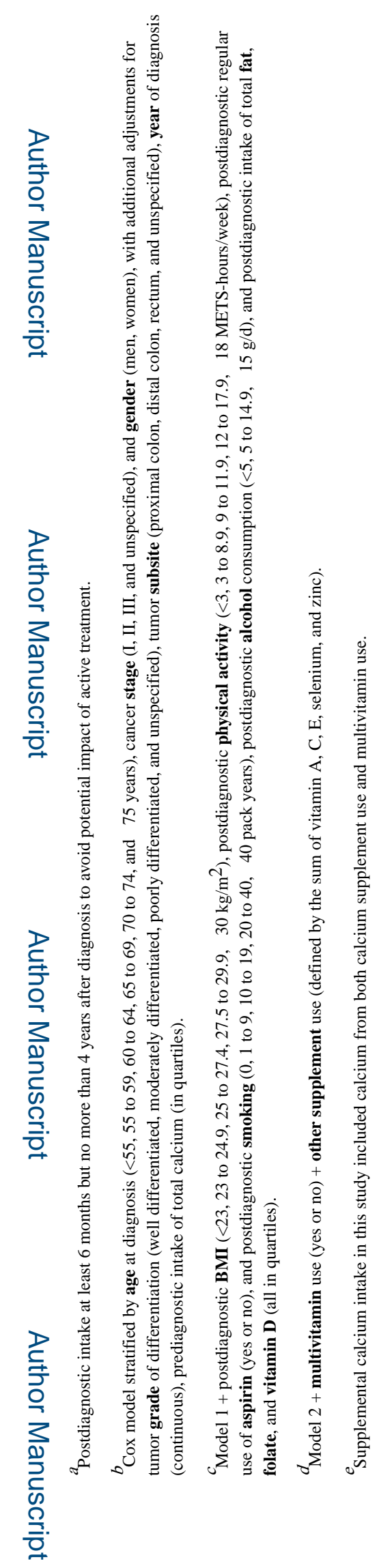

Clin Cancer Res. Author manuscript; available in PMC 2020 February 15. 


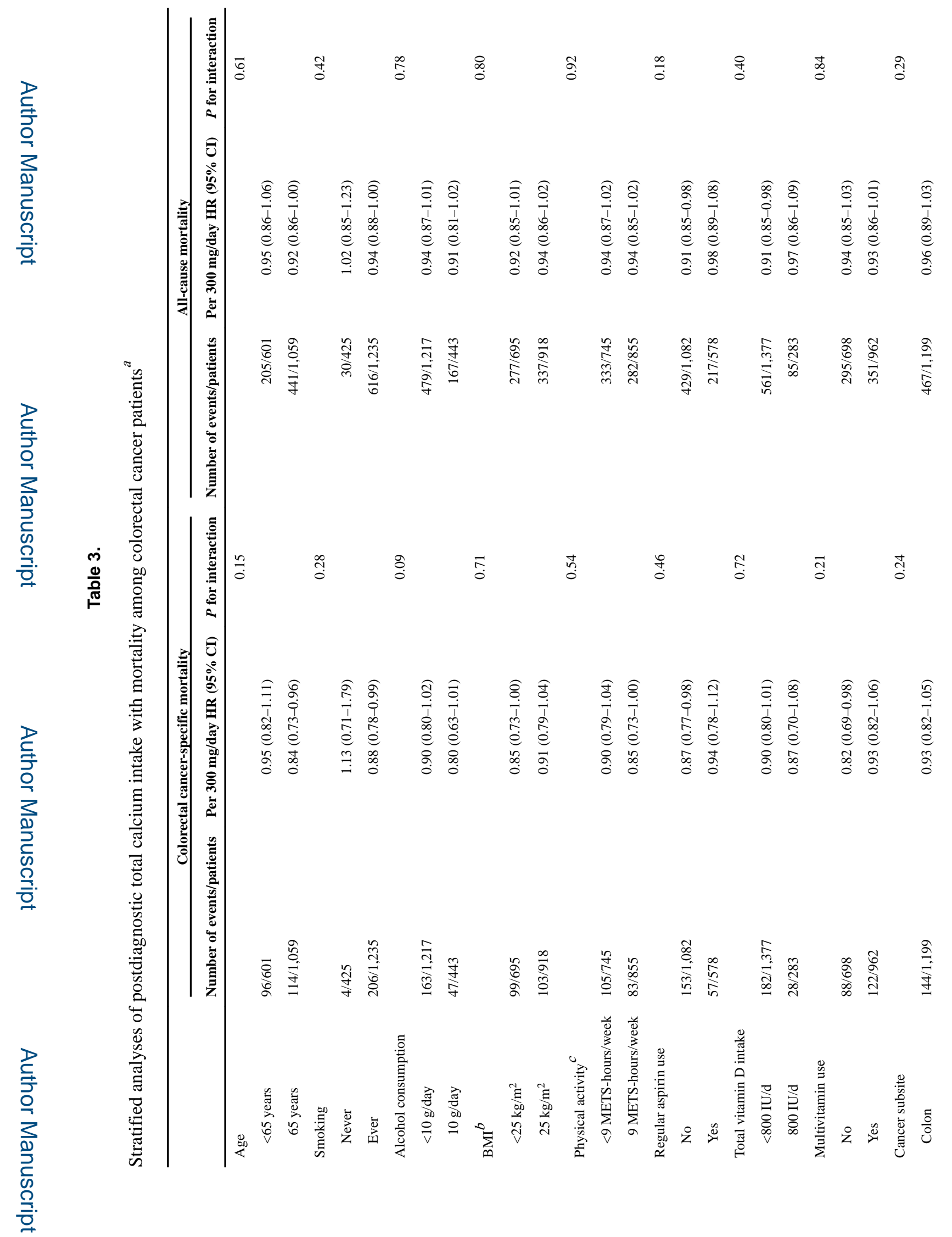

Clin Cancer Res. Author manuscript; available in PMC 2020 February 15. 


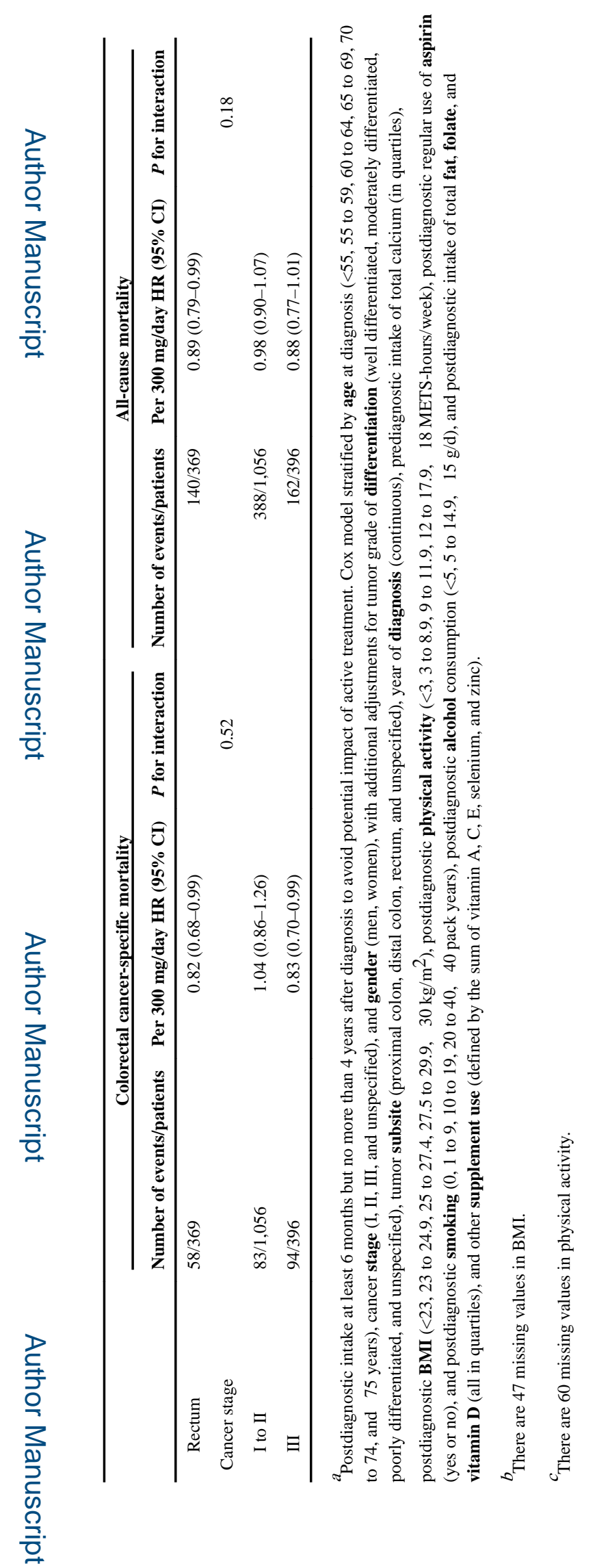

Clin Cancer Res. Author manuscript; available in PMC 2020 February 15. 


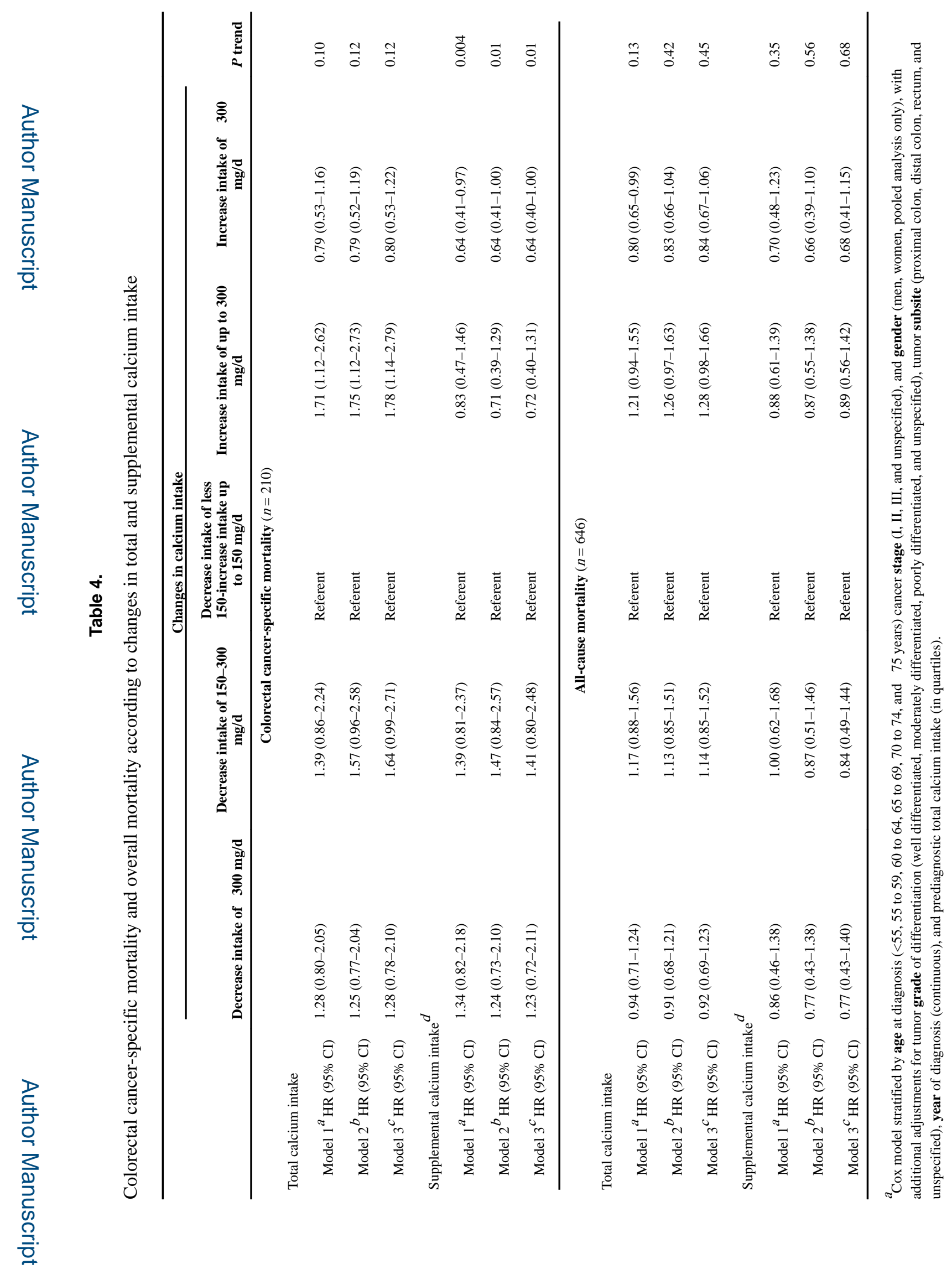

Clin Cancer Res. Author manuscript; available in PMC 2020 February 15. 


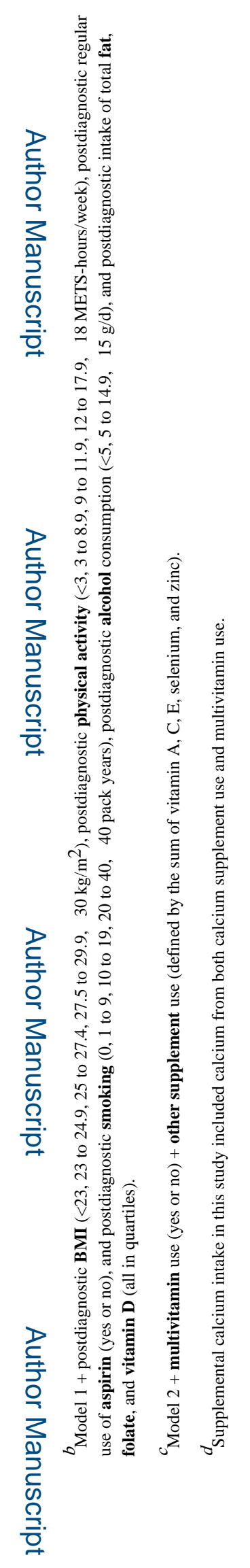

